\title{
Simple and versatile method for measuring oxygen consumption in infants
}

\author{
J. M. EVANS, O. P. GRAY, B. M. HOLLAND, AND C. A. J. WARDROP
}

From the Departments of Anaesthetics, Child Health, and Haematology, Welsh National School of Medicine, University Hospital of Wales, Cardiff

SUMMARY A simple, rapid, and accurate method for measuring oxygen consumption in infants is described. Expired gas is entrained in a stream of air drawn through a gently applied face mask. Oxygen consumption is derived from (1) gas flow rate, measured with a flowmeter, and (2) the fall in oxygen concentration of the gas mixture, measured with a paramagnetic analyser. A measurement can be made at the bedside within 2 minutes without disturbing the infant. In 17 mature 2-day-old neonates mean oxygen consumption was $6.52 \mathrm{ml} / \mathrm{kg}$ per $\mathrm{min}$, SD 0.90 , similar to that previously reported using less simple methods.

Measurements of oxygen consumption $\left(\dot{\mathrm{V}}_{2}\right)$ have been very helpful in physiological studies of the newborn, for example in determining the optimal conditions for a thermoneutral environment in term and preterm infants (Hill and Rahimtulla, 1965; Scopes and Ahmed, 1966; Hill and Robinson, 1968; Bhakoo and Scopes, 1974). They have also proved valuable in the investigation of infants undergoing cardiac catheterisation (Fixler et al., 1974) and cardiac surgery (Owen-Thomas and Meade, 1975), and in the evaluation of the effects of treatment, e.g. postoperative management (Ito et al., 1976) and phototherapy (O. Smales, unpublished, 1976).

Methods previously reported for measuring $\mathrm{O}_{2}$ consumption usually disturb the infant, are frequently time-consuming, and use relatively complicated and expensive equipment. We describe a simple method for measuring $\mathrm{O}_{2}$ consumption accurately and quickly with portable apparatus.

\section{Patients and methods}

A constant flow system is used and $\mathrm{O}_{2}$ consumption is derived by the application of the Fick principle. A clear plastic mask with a soft foam-lined rim is gently applied to the face covering the nose and mouth (Figs. 1, 2). The mask is connected to a coaxial circuit through which air is drawn at a constant flow rate. The expired gas from the infant is entrained in the gas stream drawn into the central tube. The gas is dried by silica gel before passing through a flowmeter (Rotameter). Part of the flow

Received 21 Deçember 1977.
$(0 \cdot 31 / \mathrm{min})$ is pumped to a paramagnetic oxygen analyser (Servomex 0A272) and allowed to escape to atmosphere; the remainder is drawn to waste through a needle valve and pressure regulator into a

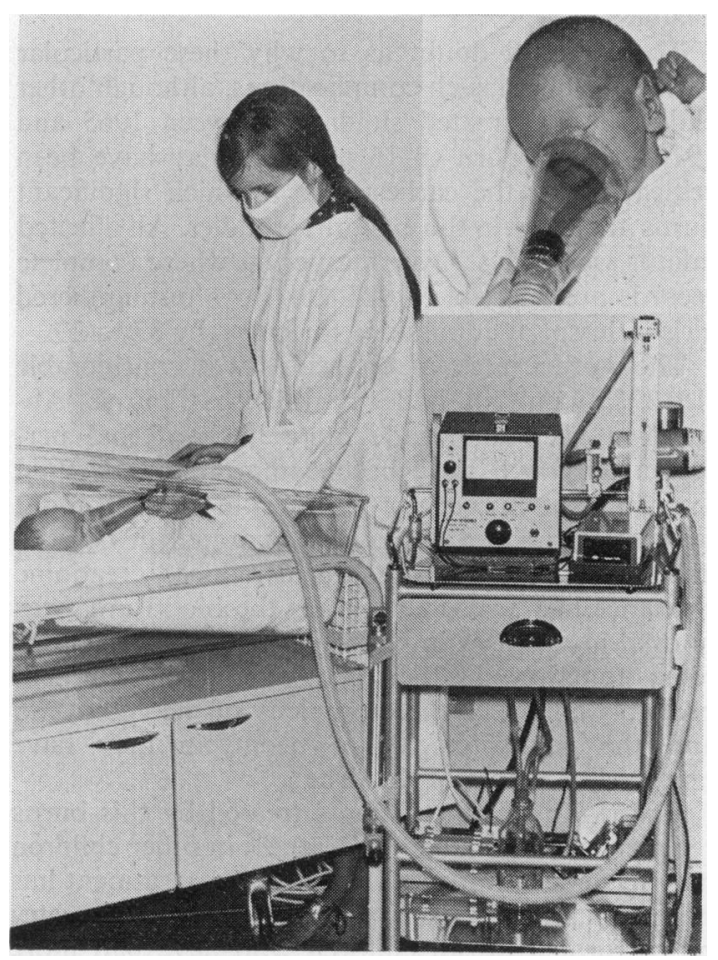

Fig. 1 The apparatus in use. 


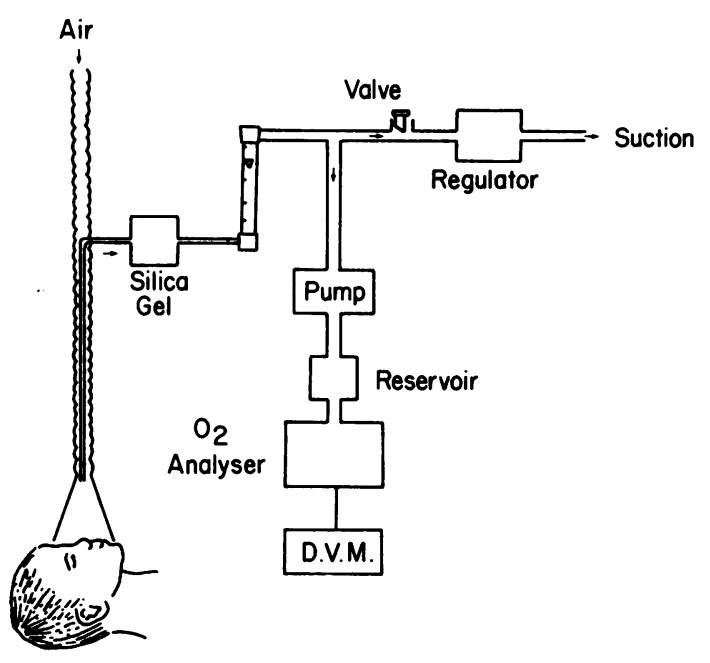

Fig. 2 System for measuring oxygen consumption. Expired gas is entrained in the constant airflow drawn into the mask through the coaxial circuit. The gas flow, after being dried, passes through a flowmeter and is sampled by the pump and paramagnetic oxygen analyser. The analyser reading is displayed on a digital voltmeter (DVM).

piped vacuum system or suction pump. $\mathrm{O}_{2}$ consumption $\left(\dot{\mathrm{Vo}}_{2}\right)$ is derived from the sample flow rate $(\dot{\mathrm{V} s})$ and fall in $\mathrm{O}_{2}$ concentration $\left(\mathrm{FDO}_{2}\right)$,

$$
\dot{\mathrm{V}} \mathrm{O}_{2}=\dot{\mathrm{V}} \mathrm{s} \times \mathrm{FDO}_{2} \text {. }
$$

Appropriate corrections are made for temperature and pressure. No allowance is made for the small volumetric difference between inspired oxygen and expired $\mathrm{CO}_{2}$. The oxygen analyser is regularly calibrated with $\mathrm{O}_{2}$ and $\mathrm{N}_{2} \mathrm{O}$, both of which are readily available (a small correction factor for the difference between $\mathrm{N}_{2}$ and $\mathrm{N}_{2} \mathrm{O}$ is applied). The apparatus is also tested at least weekly for the presence of leaks by drawing pure oxygen through the system.

A sample flow rate of $1.31 / \mathrm{min}$ per $\mathrm{kg}$ is drawn through the mask. This flow rate provides a readily measurable fall in $\mathrm{O}_{2}$ concentration (approximately $0.5 \%$ absolute) but prevents rebreathing of expired gas and loss of expired gas past the soft fitting rim of the face mask (Evans et al., 1977). Because the flowmeter tube is calibrated at atmospheric pressure, it is important that the resistance of the circuit is low so that the pressure within the flowmeter tube is atmospheric. The position of the oxygen analyser is such that it is protected from any changes in circuit pressure caused by changes in sample flow rate, which would otherwise directly affect its calibration. The sensitivity and ease of reading of the analyser is improved by the addition of a digital voltmeter. A small reservoir is placed between the pump and analyser to smooth out breath-by-breath changes in gas concentration. The volume of the reservoir is adjusted so that a steady reading is obtained within 120 seconds.

A secure airtight seal between the mask and infant is not essential. The high sample flow rate (equal to twice the approximate peak expired flow rate of the neonate) and slight subatmospheric pressure within the mask ensure that expired gas cannot escape from the mask; if a leak is present between the mask and infant, air is drawn into the mask. Since ambient air is drawn through the system additional humidification is not usually necessary; if this is essential, as part of a study of heat balance for instance, this is easily achieved by the insertion of a low resistance humidifier in the inspiratory limb of the system.

If measurements are required of the effects of critical changes in environmental factors, the mask and coaxial circuit may be replaced by a conventional head box or hood.

Laboratory verification. In order to check the accuracy and linearity of response of the system, $\mathrm{O}_{2}$ consumption was simulated by the injection of a steady flow of $\mathrm{N}_{2}$ into the central tube of the coaxial circuit. $\mathrm{N}_{2}$ entered the circuit at a range of flows from approximately 50 to $250 \mathrm{ml} / \mathrm{min}$. The true flow rate was derived using a wet-gas meter (Parkinson and Cowan Type B) and stop-watch. Appropriate corrections were applied for temperature pressure and humidity.

Clinical measurements. $\mathrm{O}_{2}$ consumption was measured in 17 healthy, term 2-day-old babies, while they were sleeping clothed in their cots 2-3 hours after feeds. The studies were made in an environment of moderate humidity which was carefully maintained within the neutral temperature range for each baby, meeting Hey's (1971) criteria for thermal neutrality.

\section{Results}

Laboratory verification. The correlation between measured and simulated $\mathrm{VO}_{2}$ is shown in Fig. 3. The $95 \%$ confidence limits of the measured values are virtually constant at approximately $\pm 1.5 \mathrm{ml} /$ min over the range $10-50 \mathrm{ml} / \mathrm{min}$.

Clinical measurements. The mean $\mathrm{V}_{2}$ was $6.52 \mathrm{ml}$ STPD $/ \mathrm{kg}$ per min, SD 0.90 . These values accord with figures obtained by other workers using both closed and open-circuit techniques (see Table). The infants' ages ranged from 32 to 60 hours, mean 48 hours; their mean weight was $3 \cdot 12 \mathrm{~kg}$, SD $0 \cdot 5$. 


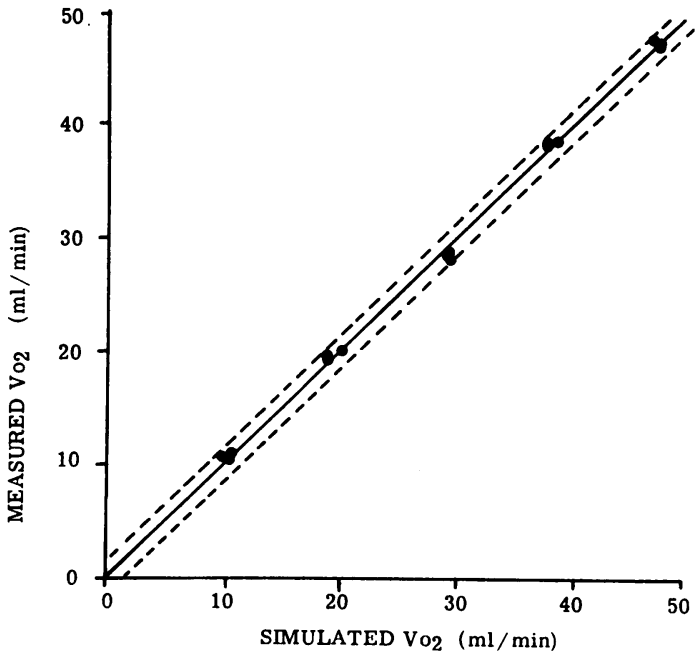

Fig. 3 Correlation (unconstrained regression line with 95\% confidence limits of a single observation) of measured $\dot{V} o_{2}$ and simulated $\dot{V} o_{2}$. Equation: $y=0.991 x+0 \cdot 19$; $\mathrm{r}=0.9991$.

Table Comparative values of $\dot{V} \mathrm{O}_{2}$ in neonates

\begin{tabular}{|c|c|c|c|}
\hline Published reports & Age $(h)$ & $\begin{array}{l}\text { No. of } \\
\text { babies }\end{array}$ & $\begin{array}{l}\mathrm{Vo}_{2}(\mathrm{ml} / \mathrm{kg} \\
\text { per min }) \\
(\text { mean } \pm S D)\end{array}$ \\
\hline $\begin{array}{l}\text { Present method } \\
\text { Hill and Rahimtulla (1965) }\end{array}$ & $32-60$ & 17 & $6 \cdot 52 \pm 0.90$ \\
\hline $\begin{array}{l}\text { Hill and Robinson (1968) } \\
\text { Scopes and Ahmed (1966) } \\
\text { Ito et al. (1976) }\end{array}$ & $\begin{array}{l}48-96 \\
33-47 \\
1 w\end{array}$ & $\begin{array}{l}16 \\
11 \\
39\end{array}$ & $\begin{array}{l}6 \cdot 70 \pm 0 \cdot 70 \\
6 \cdot 44 \pm 1 \cdot 21 \\
5 \cdot 96 \pm 0 \cdot 77\end{array}$ \\
\hline
\end{tabular}

\section{Discussion}

Other methods (Hill and Rahimtulla, 1965; Hill and Robinson, 1968; Scopes and Ahmed, 1966; Stoker et al., 1973; Fixler et al., 1974; Smales, 1978) involve placing the infant in a sealed box or collecting expired air from a hood or tightly applied mask to avoid leakages. The high fresh gas flow used in our method not only ensures that expired gas does not escape past leaks at the rim of the mask (Evans et al., 1977) but also ensures that rebreathing of expired gas does not occur. At gas flows of less than twice the minute volume, rebreathing is likely to occur (Willis et al., 1975). Assuming, in the neonate, a minute volume of $300 \mathrm{ml} / \mathrm{kg}$ per min the fresh gas flow should therefore exceed $600 \mathrm{ml} / \mathrm{kg}$ per min. The use of lower fresh gas flows (500 to $1000 \mathrm{ml} / \mathrm{min}$; Smales, 1978) will almost certainly result in $\mathrm{CO}_{2}$ retention in all but the smallest neonates; this cannot be excluded by measurements of $\mathrm{CO}_{2}$ concentration in mixed expired gas obtained from a T-piece arrangement. The Servomex OA272 analyser used in the present system is ideal for this type of investigation and obviates the need for additional amplification, recording, and calibration equipment.

The present method can be quickly and repeatedly performed from within minutes of birth and produces accurate results without disturbing the infant. The equipment is relatively simple, inexpensive, and portable. The measurement of $\mathrm{O}_{2}$ consumption by this method has many potential applications in special-care nurseries and paediatric wards. We have used it to make several hundred measurements of $\mathrm{O}_{2}$ consumption in neonates and infants in the labour wards, special care nursery, and in the follow-up of older infants as outpatients.

We gratefully acknowledge the assistance of Sister I. Wardrop, of the Nursing Staff of the Maternity Department, University Hospital of Wales, and of Mrs Jeanette Brown, whe typed the manuscript.

\section{References}

Bhakoo, O. N., and Scopes, J. W. (1974). Minimal rates of oxygen consumption in small-for-dates babies during the first week of life. Archives of Disease in Childhood, 49, 583-585.

Evans, J. M., Hogg, M. I. J., and Rosen, M. (1977). Measurement of carbon dioxide output, alveolar carbon dioxide concentration and alveolar ventilation in the neonate. British Journal of Anaesthesia, 49, 453-456.

Fixler, D. E., Carrell, T., Browne, R., Willis, K., and Miller, W. W. (1974). Oxygen consumption in infants and children during cardiac catheterization under different sedation regimes. Circulation, 50, 788-794.

Hey, E. (1971). The care of babies in incubators. Recent Advances in Paediatrics, 4th ed., p. 180. Ed. by D. Gairdner and D. Hull. Churchill, London.

Hill, J. R., and Rahimtulla, K. A. (1965). Heat balance and the metabolic rate of newborn babies in relation to environmental temperature; and the effect of age and weight on basal metabolic rate. Journal of Physiology, 180, 239-265.

Hill, J. R., and Robinson, D. C. (1968). Oxygen consumption in normally grown, small-for dates and large-for-dates newborn infants. Journal of Physiology, 199, 685-703.

Ito, T., Iyomasa, Y., and Inoue, T. (1976). Changes in postoperative oxygen consumption of the new born. Journal of Pediatric Surgery, 11, 495-503.

Owen-Thomas, J. B., and Meade, F. (1975). A non-invasive method of continuous measurement of gas exchange in spontaneously breathing infants in a thermal neutral environment. (Abst.) British Journal of Anaesthesia, 47, 637.

Scopes, J. W., and Ahmed, I. (1966). Minimal rates of oxygen consumption in sick and premature newborn infants. Archives of Disease in Childhood, 41, 407-416.

Smales, O. (1978). Simple method for measuring oxygen consumption in babies. Archives of Disease in Childhood, 53, 53-57. 
Stoker, J. B., Kappagoda, C. T., Thenabadu, P. N., and Linden, R. J. (1973). A simple method for the measurement of oxygen consumption. Journal of Applied Physiology, 35, 748-750.

Willis, B. A., Pender, J. W., and Mapleson, W. W. (1975). Rebreathing in a T-piece: volunteer and theoretical studies of the Jackson-Rees modification of Ayre's T- piece during spontaneous respiration. British Journal of Anaesthesia, 47, 1239.

Correspondence to Professor O. P. Gray, Department of Child Health, Welsh National School of Medicine, Heath Park, Cardiff CF4 4XN.

The following articles will appear in future issues of this journal:

Isolated ACTH deficiency: metabolic and endocrine studies in a seven-year-old boy. A. Aynsley-Green, M. W. Moncrieff, S. Ratter, C. R. Benedict, C. N. Storrs, and R. H. Wilkinson.

Danger of bucolome in infants with hyperbilirubinaemia: experimental evidence. R. Semba, H. Sato, and H. Yamamura.

Nebulised sodium cromoglycate in the preschool wheezy child. W. Lenney and A. D. Milner.

Growth impairment in children treated for brain tumours. S. M. Shalet, C. G. Beardwell, B. M. Aarons, D. Pearson, and P. H. Morris Jones.

Renin and aldosterone response in human newborns to acute change in blood volume. M. J. Dillon, K.B. Rajani, V. Shah, J. M. Ryness, and R. D. G. Milner.

Gluten challenge in treated coeliac disease. S. M. Packer, V. Charlton, J.W. Keeling, R. A. Risdon, D. Ogilvie, R. J. Rowlatt, V. F. Larcher, and J. T. Harries.

Pulmonary interstitial emphysema requiring lobectomy: a complication of assisted ventilation. J. H. Drew, L. I. Landau, C. M. Acton, M. Kent, and P. E. Campbell.

Infantile cortical hyperostosis with raised immunoglobulins. V. Ramchander, and R. Ramkissoon. 